\title{
Corrigendum: Neuronal PTP1B regulates body weight, adiposity and leptin action
}

Kendra K Bence, Mirela Delibegovic, Bingzhong Xue, Cem Z Gorgun, Gokhan S Hotamisligil, Benjamin G Neel \& Barbara B Kahn Nat. Med. 12, 917-924 (2006); published online 16 July 2006; corrected after print 7 January 2010

In the version of this article initially published, the source of the Nestin-Cre mice was incorrectly stated as Jackson Labs. The correct source of the Nestin-Cre mice (which were on a mixed 129/Sv $\times$ C57BL/6 hybrid background) was R. Klein (Max Planck Institute of Neurobiology). The error has been corrected in the HTML and PDF versions of the article.

\section{Addendum: Neuronal PTP1B regulates body weight, adiposity and leptin action}

Kendra K Bence, Mirela Delibegovic, Bingzhong Xue, Cem Z Gorgun, Gokhan S Hotamisligil, Benjamin G Neel \& Barbara B Kahn Nat. Med. 12, 917-924 (2006); published online 16 July 2006; corrected after print 7 January 2010; addendum published after print 7 January 2010

The widespread use of Nestin-Cre mice has led to an increasing awareness of potential diet- and strain-dependent differences in body weight in these mice. Accordingly, we have tested the effect of Nestin-Cre alone in several strains of mice and have observed marked differences in body weight between Nestin-Cre and wild-type mice fed chow in some, but not all, strains (data not shown). Given these strain differences, and to rule out potential spurious results, we would like to add additional control data from experiments performed at the time of the original studies in our paper showing no effect of Nestin-Cre expression alone on body weight (Fig. 1).

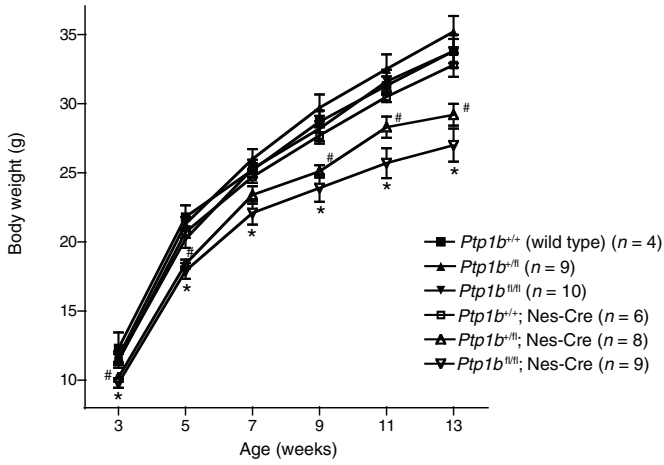

Figure 1 Body weight curves of male mice fed a high-fat diet from weaning ( 3 weeks of age). Ptp $1 b^{+/ f l}$ Nes-Cre and Ptp $1 b^{f / f l}$ Nes-Cre mice weighed significantly less than $P \operatorname{tp} 1 b^{+/+}$Nes-Cre mice by two-way ANOVA with repeated measures $\left(P=0.013\right.$ and $P=0.003$, respectively); \#P<0.05 $P$ tp $1 b^{+/ f l}$ NesCre versus $P \operatorname{tp} 1 b^{+/+}$Nes-Cre, and ${ }^{*} P<0.05 P \operatorname{tp} 1 b^{f / / f l}$ Nes-Cre versus $P t p 1 b^{+/+}$Nes-Cre by unpaired two-tailed Student's $t$ test at the indicated time points. Body weights were not different between $P t p 1 b^{+/+}$Nes-Cre mice and Ptp $1 b^{+/+}$(wild-type), Ptp $1 b^{+/ f \mid}$ or Ptp $1 b^{f l / f l}$ mice fed a high-fat diet from weaning (by two-way ANOVA with repeated measures or two-tailed Student's $t$ test). All mice were on a mixed 129/Sv $\times$ C57BL/6 hybrid background.

\section{Erratum: Reducing endoplasmic reticulum stress through a macrophage lipid chaperone alleviates atherosclerosis}

Ebru Erbay, Vladimir R Babaev, Jared R Mayers, Liza Makowski, Khanichi N Charles, Melinda E Snitow, Sergio Fazio, Michelle M Wiest, Steven M Watkins, MacRae F Linton \& Gökhan S Hotamisligil

Nat. Med. 15, 1383-1391 (2009); published online 29 November 2009; corrected after print 4 February 2010

In the version of this article initially published, the official symbol for the gene encoding the aP2 protein was misidentified as Tcfap $2 a$ (the gene symbol for the transcription factor AP-2). The correct gene symbol is Fabp4. In no instances anywhere in the study was AP-2 examined. Additionally, Supplementary Figure 2a should also have been cited where Figure $2 \mathrm{c}$ was cited. The errors have been corrected in the HTML and PDF versions of the article. 